\title{
Ground penetrating radar assessment of historical buildings: the study of the roofs, columns and ground of Santa Maria del Mar, in Barcelona
}

\author{
GPR assessment of the basilica Santa Maria del Mar
}

\author{
V. Perez-Gracia \\ Dept. Strength of Materials and Structural Engineering \\ Universitat Politècnica de Catalunya, Barcelona-Tech. \\ C/ Urgell 187, 08036-Barcelona \\ Spain \\ vega.pere@upc.edu
}

\author{
O. Caselles, J. Clapes \\ Dpt. Ingeniería del Terreno, Cartográfica y Geofísica \\ Universitat Politècnica de Catalunya, Barcelona-Tech. \\ C/Jordi Girona 1-3. 08034-Barcelona \\ Spain \\ Oriol.caselles@upc.edu
}

\begin{abstract}
Santa Maria del Mar is a magnificent gothic church built between 1329 and 1383 in a neighbourhood outside the city walls, over the remains of a more ancient church. The inhabitants of this district (merchants, downloaders of the port, ship-owners artisans and craftsmen) contributed and took part in the construction of this building. Nowadays it is one of the most representative gothic buildings of Barcelona. The structure was completely studied with GPR in order to obtain useful information for a further restoration. Some of the most interesting results were obtained during the evaluation of the vaults and roofs of the building. Radar images demonstrate that the inner structure was designed in order to diminish the load on the arches and walls. Hollow elements were used to support partly the roof in some areas. Moreover, walls, floors and columns were also assessed, and also the ground outside the building. A large number of graves were located under the church floor, but also some of the radar images suggest the existence of large underground walls. The GPR study of the columns and walls was completed with a seismic survey that demonstrates the existence of zones of non-consolidated materials and defined the joints of the ashlars.
\end{abstract}

Keywords-Ground penetrating radar, building assessment, cultural heritage, seismic tomography, geopphysical survey

\section{INTRODUCTION}

The Basilica of Santa Maria del Mar is placed in the neighbourhood La Ribera, in Barcelona. This district was the commercial centre of the city during the centuries XII to XV. In this period, many merchants, important artisans and minor nobles built their residences in the area. In the 1329 began the works for the construction of the church that is known nowadays as Basilica de Santa Maria del Mar, probably over older remains. Some authors indicate that those remains belong to a Pre-Romanesque chapel, while others point to roman structures. Berenguer de Montagut was the main foreman, being helped by Ramon Despuig. The church was finished in 1383, and belonged exclusively to the parishioners of the district who were supported the cost of the construction with their own work or with money.
The actual building is one of the most representative gothic buildings of Barcelona. The church has three naves, and slender octagonal columns. Those columns and the main walls support the weight of the structure (Figure 1). Despite the general good state of conservation of the structure, visible damage in some parts indicate the need of restoration tasks. Therefore, a restoration project was planned, involving also the archaeological study under the floor of the building.
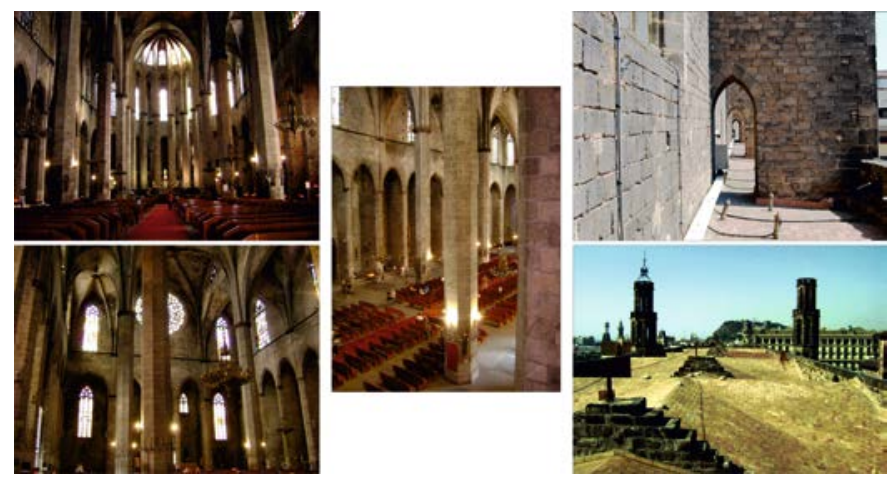

Fig. 1. Images of the Basilica. The slender columns divides the space in three naves.

The restoration project requires as much information as possible about the structure of the building and the possible damage. As part of preliminary studies, it was decided assess the structure by means of some non-destructive testing surveys, being those analysis previous to a more invasive explorations. Hence, after the visual inspection, ground penetrating radar (GPR) survey was combined with seismic tomography.

Non-destructive testing is usually recommended as previous analysis, being able to apply different methodologies to masonry structures [1]. The use of GPR surveys and different seismic methodologies in Cultural Heritage assessment showed their ability to determine zones where further studies can be required. Both techniques, based on the 
detection of electromagnetic and elastic waves respectively, are perfectly capable to detect damaged zones (e.g., [2], [3], [4]) and also to inspect the arrangement of internal structures in constructive elements (e.g., [5], [6]).

\section{EQUIPMENT AND RADAR SURVEY}

\section{A. Equipment}

A commercial GPR system SIR-3000 from GSSI was used with different antennas. In the survey, $200 \mathrm{MHz}$ and $400 \mathrm{MHz}$ centre frequency antennas were used in order to assess the soil and the roof. The survey of columns and walls was carried out with a $900 \mathrm{MHz}$ centre frequency antenna. A survey wheel was used in order to locate the antenna along each radar line. The surveyed zones are presented marked in yellow in the Figure 2.
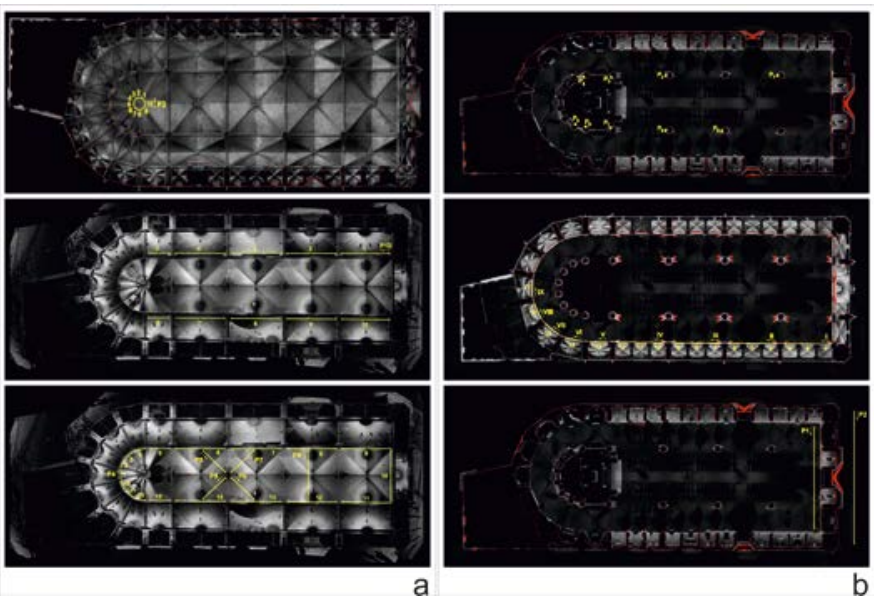

Fig. 2. Radar lines marked in yellow on the images of the church. a) Surveyed zones in the roof. b) Surveyed zones in the floor and columns.

\section{B. Radar survey}

The assessment was focused in three areas of the church: roof, columns and floor.

The survey in the roof was applied to all the different structures in the zone, being mainly focused in determining the thickness of the different structures and the existence of possible voids. This information was crucial in order to determine the weight supported by the slender columns and main walls. Besides, the elevated structure and its slenderness insinuate an important reduction of the roofing and upper walls weight, being the evaluation of the mechanisms used to reduce the loads a fundamental information in the later restoration of the building. In the case of homogeneous elements, the apparent thickness of the different structural members would introduce a load greater than the weight that could be supported by walls and columns. Therefore, the radar lines covered the perimeter, the cylindrical structure over the main vault, and the vaults of the naves.

The survey in the floor was carried out in order to determine possible buried targets, defining also those characteristics of the soil that could affect the foundation of the main walls. As consequence, the radar lines were along the perimeter of the church and inside and outside of the front door wall.

Finally, after the visual inspection, some columns were also surveyed by means of GPR and seismic tomography. The objective was defining the inner arrangement of the ashlars and detecting zones of the stones with damage. The knowledge about the structure of the columns and their state of conservation is needed in order to define proper models and to compute an accurate structural analysis of the building.

\section{RESULTS OF THE STUDY OF THE ROOF}

Radar data obtained in the roof allows differentiating four main features (see Figure 3). The first feature is corresponding to the anomalies associated to the structure of the vaults (labelled A in Figure 3). This structure seems to be composed by three layers with different radius of curvature. The anomaly centred on the external vault could be caused by the reflection on the keystone of the vault. The radar image is clearly regular in this zone; as consequence, materials in this area seem to be homogeneous. The second feature (labelled B in Figure 3 ) is a zone in the radar data characterized by small hyperbolas. The pattern could show the presence of heterogeneous filling. A possible hypothesis is the presence of several hollow ceramic elements and mortar. This possible filling could help in diminish the weigh to the roof structures. Besides, this characteristic could explicate the small hyperbolas recorded in radar data. Moreover, the distribution of the hyperbolas, corresponding to different two-way travel times, seems to indicate that those possible hollow targets could be placed at different depths. The zone is located between each two arches, being the widest part of the roof.

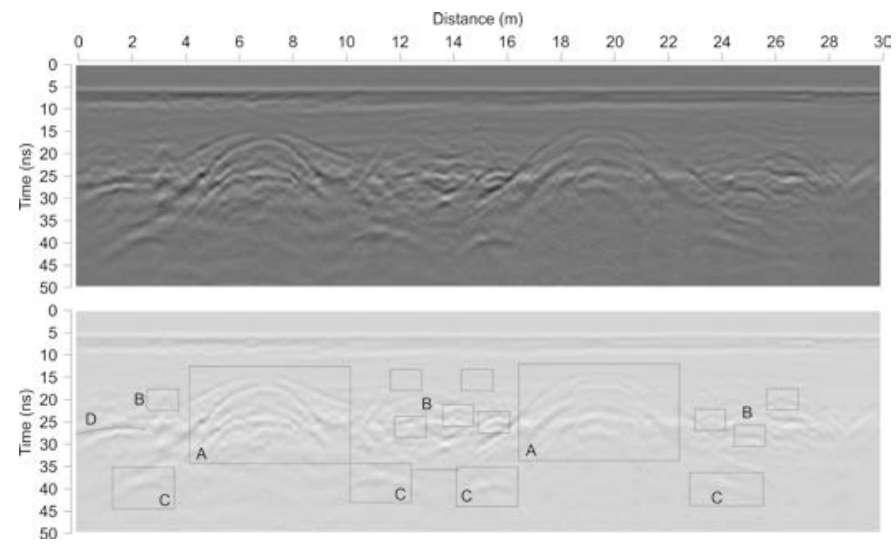

Fig. 3. Detail of the radar image obtained in the wall and possible interpretation. A) Reflections on the structure of the vaults. B) Reflections on heterogeneus filling between vaults. C) Reflection on chapitels of the colums supporting the vaults. D) Reflection on homogeneous materials between the vaults and the walls.

The third feature corresponds to a zone in the radargram that could be associated to the junction between arches and columns. The fourth feature is a flat and homogeneous anomaly that could be related to the junction between the arch and the main wall. This last part seems to be built with homogeneous stones. Figure 4 shows a drawing of these four possible zones deduced from the GPR survey. The heterogeneous and hollow materials between the arches could 
be an architectural solution that would help to decrease the weight of the roof without reducing bearing capacity. The homogenous zones could be composed by ashlars.
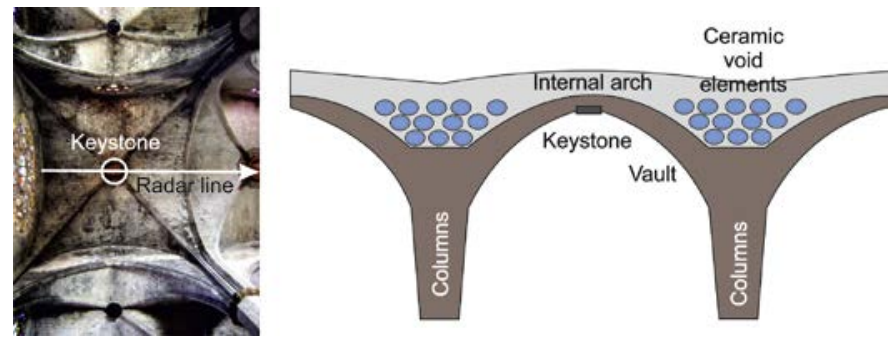

Fig. 4. Photograph of the vault showing the location of the GPR line on the roof and the keystone, and drawing of the possible GPR data inerpretation.

Figure 5 shows a detail of radar image obtained in the zone most likely built with those heterogeneous and hollow pieces, which were used to reduce the weight in the area between columns. In this image, the most homogeneous zone over the reflection associated to the vaults can be clearly distinguished from the area between vaults, where the great number of anomalies indicates the existence of irregular targets and heterogeneous filling. Moreover, the high amplitude of some of those anomalies reveals the important change in the wave velocity, suggesting reflections on voids or hollow targets.

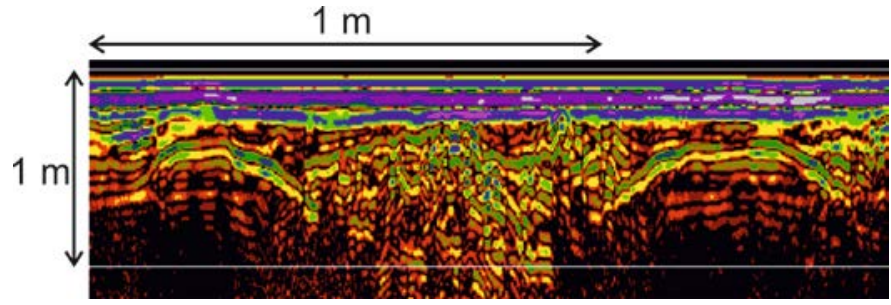

Fig. 5. Detail of the anomalies between the vaults, corresponding to a void elements, most likely amphores or ceramic bottles.

\section{RESULTS OF THE GROUND ASSESSMENT}

The results concerning the ground under the main façade shows the existence of a slab inside of the Basilica. This slab is most likely not completely homogeneous because GPR images presents some changes that could be related to alterations in the upper pavement or in its inner conditions. Under this slab, the ground seems to be homogeneous, being detected a possible geological layer at about $2.5 \mathrm{~m}$ deep. However, coincident with the two supporting structures at both sides of the front door, two important anomalies could be caused by reflections on the foundations of the church. Other anomalies could be associated to graves or buried structures. Figure 6 presents a radargram obtained in this zone, where the anomalies are clearly visible.

Radar data obtained outside the church (Figure 7) also contains a large number of anomalies that could be associated to walls remains of ancient houses close the church.

Therefore, the results from the study of the ground suggest that the structure is built over a homogeneous layer with few irregular geological targets, but the existence of cultural heritage remains outside the basilica. Inside the basilica the anomalies could be associated to graves and foundations.

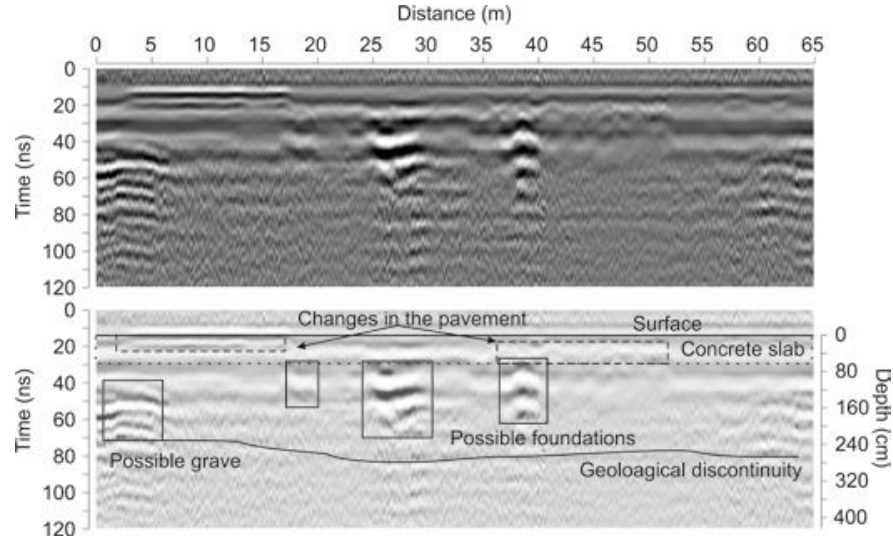

Fig. 6. Radar data showing important anomalies that could be associated to foundations, in the radar line inside the church, along the main façade.

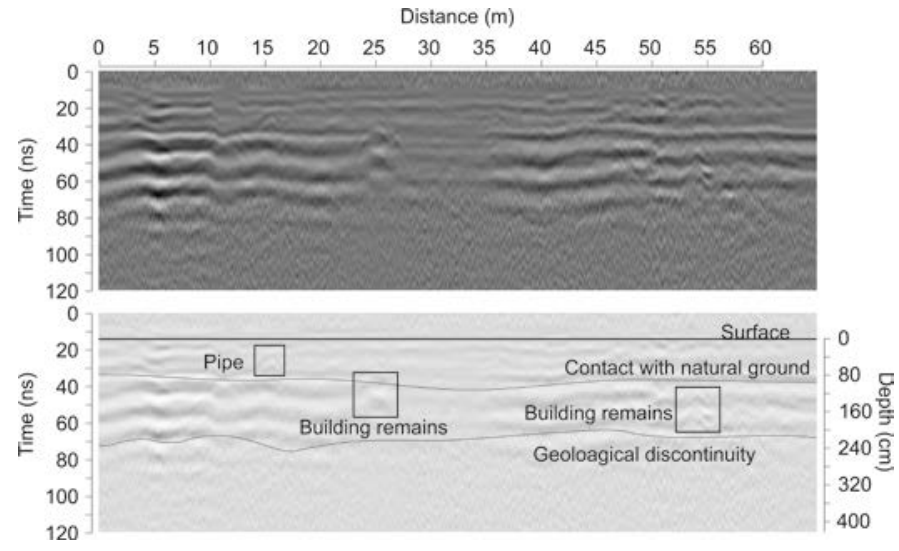

Fig. 7. Radar data obtained in front of the main façade, outside the church.

\section{RESULTS OF THE STUDY OF COLUMNS}

The assessment of columns demonstrates a correct state of conservation of many of them. Radar images show the inner arrangement of the ashlars and the homogeneity of the images seems indicating that no important damage affect the structures. Figure 8 presents GPR images obtained in sections of two of the assessed columns.
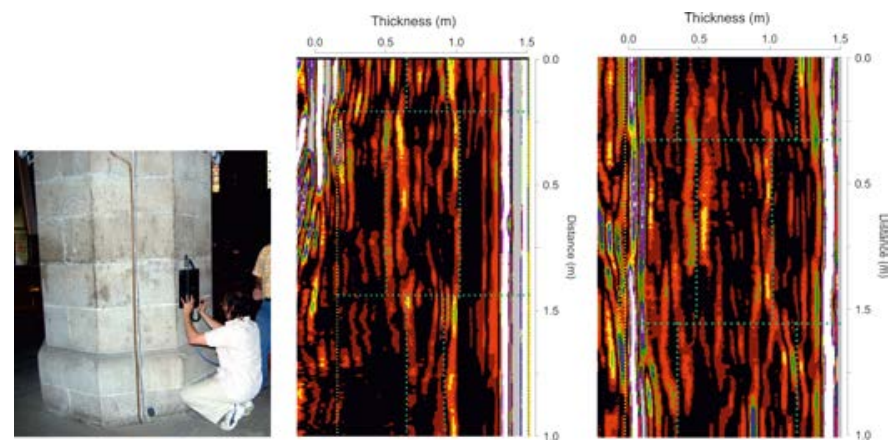

Fig. 8. Radar data acquisition during the columns assessment and, radar data obtained in the radar lines along two of the columns of the church. 
Reflections on the contacts between stones are visible, and the lack of strong anomalies highlights the good state of conservation, being the main reflections caused in the joints between ashlars.

The study was complemented with a seismic tomography of some of the columns. The results present the distribution of the velocity of a mechanical wave in a section of the structure (see Figure 9). The source is a hammer, and the energy arrives to a receivers (geophones) placed around the selected section. The objective is defining those elements that present differences in the elastic properties, being characterized by the seismic wave velocities.

Higher wave velocities correspond to a more homogeneous rock, while possible damage corresponds to a lower velocities and contacts between ashlars.
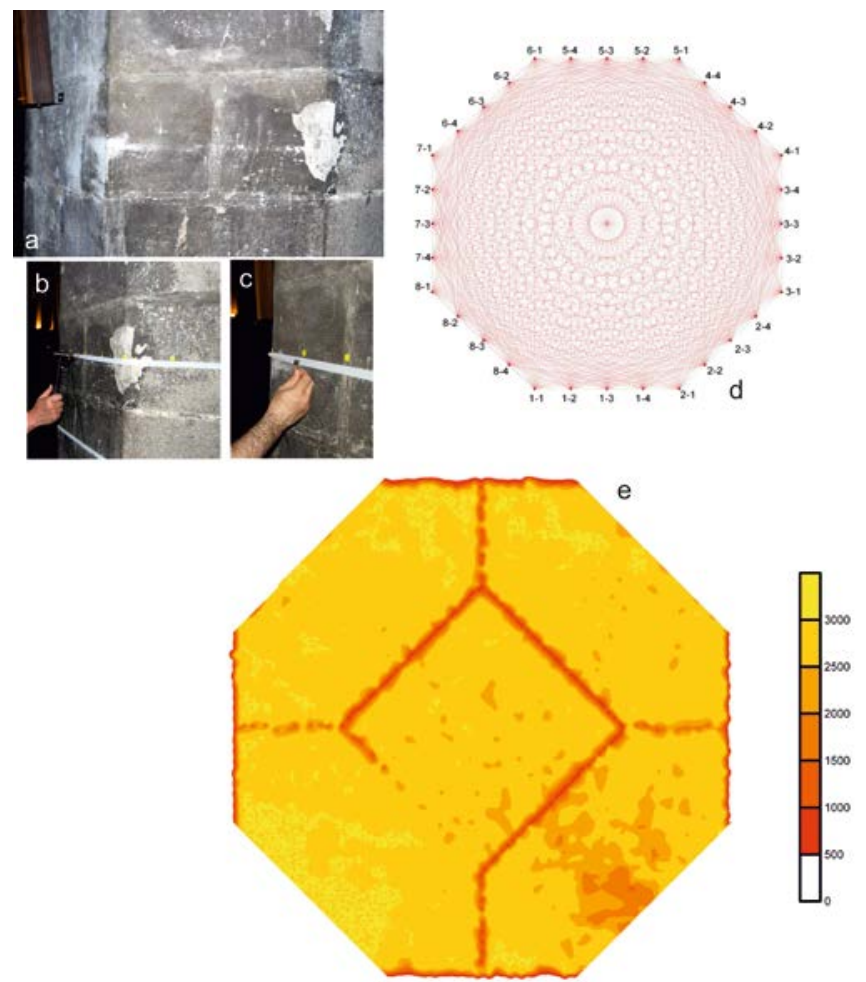

Fig. 9. Seismic tomography. a) Assessed column. b) The hammer is used as a source of the seismic waves. c) The receivers are geophons. d) Trajectories of the wave in the hypothetic case of a homogeneous material. e) Tomography of the colums.

The result defined clearly the contacts between the stones, indicating the existence of a middle squared ahslar. In addition some areas showing lower velocities (Figure 9) demonstrate that in some parts the stone is damaged, most likely fissured.

\section{DISCUSSION AND CONCLUSION}

The assessment of the Basilica was mainly focused in the study of the roof and the supporting columns, although the ground was also surveyed in the most relevant zones.
The study of the roof demonstrates the existence of materials used in the widest parts with the objective of reduce the weight of the structure and the load over the columns. These elements could be hollow ceramic vessels or similar objects, and appear in the roof just over the columns and between the vaults. GPR technique is demonstrated to be appropriate to study these changes in the materials, and highlights the interesting solution applied in order to decrease the loads as consequence as the roofing weight.

The analysis of the columns demonstrates the existence of a squared stone in the centre of the structure, being the other stones placed around this central ashlar. However, GPR only provides information about the structural arrangement. It is difficult to define the existence of possible damage zones without additional information. Therefore, the seismic study complements the radar analysis, providing information about the seismic wave velocity in surveyed sections of the column, being this velocity related to the state of conservation of the stones. The seismic tomography images show the structural arrangement of the ashlars inside one column, but it also reveals those zones where the wave velocity is slower. The lower velocities correspond to a more heterogeneous material and damage parts of the ahslar.

\section{ACKNOWLEDGMENT}

This work has been partially funded by the project "New Integrated Knowledge based approaches to the protection of cultural heritage from Earthquake-induced Risk-NIKER" funded by the European Commission (Grant Agreement $n^{\circ}$ 244123), and by the Spanish Government, by the European Commission and with FEDER funds, through the research projects: CGL2008-00869/BTE and CGL2011-23621. The work is also a contribution to the EU funded COST Action TU1208, "Civil Engineering Applications of Ground Penetrating Radar"

\section{REFERENCES}

[1] L. Binda, A. Saisi, C. Tiraboschi, "Investigation procedures for the diagnosis of historic masonries,” Construction and Building Materials 14, pp. 199-233, 2000.

[2] A. Calia, M. Lettieri, G. Leucci, L. Matera, R. Persico, M. Sileo, "The mosaic of the crypt of St. Nicholas in Bari (Italy): integrated GPR and laboratory diagnostic study,” Journal of Archaeological Science 40, pp. 4162-4169, 2013

[3] G. Leucci, R. Cataldo, G. De Nunzio, “Assessment of fractures in some columns inside the crypt of the Cattedrale di Otranto using integrated geophysical methods,” Journal of Archaeological Science 34, pp. 222232, 2007.

[4] G. Leucci, R. Persico, F. Soldovieri, "Detection of fractures from GPR data: the case history of the Cathedral of Otranto," Journal of Geophysics and Engineering 4(4), pp 452-461, 2007.

[5] V. Pérez-Gracia, J.O. Caselles, J. Clapés, G. Martinez, R. Osorio, “Nondestructive analysis in cultural heritage buildings: Evaluating the Mallorca cathedral supporting structures,” NDT\&E International 59, pp. 40-47,2013.

[6] Binda L, Saisi A, Tiraboschi C, Valle S, Colla C, Forde M (2003) Application of sonic and radar tests on the piers and walls of the Cathedral of Noto. Construction and Building Materials 17: 613-627. 